\title{
Integrated Performance Measurement Systems: Implementation Case Studies
}

\author{
U. S. Bititci, A. S. Carrie, T. Turner and S. Lutz \\ Centre for Strategic Manufacturing, University of Strathclyde \\ Glasgow, UK, Tel: 44-141 548 2015, Fax: 44-141 5520557 , \\ e-mailcsm@dmem.strath.ac.uk
}

\begin{abstract}
Identifying a relevant and simple set of performance measures is a common problem faced by most companies. This paper presents the work done at University of Strathclyde to address this issue. The Integrated Performance Measurement System Reference Model and the associated Audit Method is introduced. Their use is described through three case studies.
\end{abstract}

Key Words
Performance Measurement, Models, Audits, Case Studies

\section{INTRODUCTION}

The objective of this paper is to demonstrate the practical use of the Integrated Performance Measurement Systems (IPMS) Reference Model and the associated Audit Method, which have been developed at the Centre for Strategic Manufacturing as a result of EPSRC and industry funded research programmes.

The paper first provides a background to the research and then goes on to describe the theoretical basis of the model. The use of the Reference Model and the Audit Method is then demonstrated through three different case studies. 


\section{BACKGROUND}

Over the recent years there has been considerable emphasis on performance measurement in all-industrial and commercial organisations as a means to:

- Control the strategic direction of the business and its constituent parts.

- Drive improvement programmes in line with the strategic direction

- Maximise the effect of the improvement effort.

This emphasis has led to the development of various approaches to design of performance measurement systems by academics, consultants and industrialists (Kaplan and Norton, 1992; Russell, 1992; Neely et al, 1995; Neely et al 1996). Published case studies report various degrees of success in achieving the intended objectives (Gelders et. al, 1993).

Early stages of the research described in this paper established that an integrated, robust, efficient and effective performance measurement system should fulfil the following requirements (Bititci et al. 1996).

- reflect stakeholders requirements

- reflect external/competitive position of an organisation

- reflect competitive criteria of the organisations markets

- differentiate between control and improvement measures

- facilitate strategy development

- deploy strategic objectives through a logical path to business processes

- focus on critical areas of the business

- be expressed in a locally meaningful terminology

- facilitate resource bargaining

- facilitate performance planning

- promote proactive management by focusing on leading measures

- accommodate both quantitative and qualitative measures

- measure organisational capability and learning where appropriate

- use measures at correct levels

- promote understanding of the relationships between various measures

- facilitate simple reporting - demonstrating trends where possible

The work also established that despite the availability of various approaches to performance measurement systems design (Maskell, 1992; Kaplan and Norton, 1996; Cross and Lynch, 1989; Dixon et al, 1990; Globerson, 1985), a reference model, which fulfilled the above requirements, was not available (Bititci et al, 1996). Consequently, the work progress towards developing:

- A Reference Model for an integrated performance measurement system.

- An Audit Method to assess the integrity of performance measurement systems. 


\section{THE IPMS REFERENCE MODEL}

The Reference Model was developed following extensive research. This research focused on two primary areas:

- Past and present academic work.

- Good and bad industrial practices.

A framework based on Beer's Viable Systems Model (Beer, 1985) has been used to develop a cybernetic control structure which integrates all of the key concepts with the practices identified throughout the research. This structure consists of four levels. These are Business, Business Unit, Business Process and Activity levels. The Reference Model at each of its four levels considers four elements. These are Stakeholders Requirements, External Monitor, Objectives and Performance Measures.

The Reference Model requires that, at each level of the business the organisation:

- Recognises and understands the requirements of its Stakeholders.

- Monitors its external position against competitors and world class performance to identify the development needs of the business.

- Sets objectives based on implications and criticality of the development gaps together with appropriate targets and time scales.

- Monitors and reviews these objectives through performance measures reports.

- Deploys its objectives to lower levels.

Figure 1 illustrates the final structure of the Reference Model. There are a number of principles integrated within the Reference Model, which the reader should be aware of to form a complete understanding of the Reference Model. These have been described in detail in previous publications (Bititci et al, 1997).

\section{THE AUDIT PROCESS}

An Audit Method has been developed, which allows assessment of the integrity of an organisation's performance measurement system against the Reference Model. The audit method examines:

- the level of conformity with the structure of the reference model

- appropriateness of the performance measures used

- appropriateness of the targets and objectives set

Typically an audit identifies issues such as:

- Absence of performance measures critical to the strategic objectives

- Use of surplus and meaningless performance measures

- Wrong emphasis on measures 
- Lack of deployment of measures due to absence of Criticality, Trunsduction and Resource Bargaining

- Confusion between control and improvement measures

- Absence of a logical system for performance planning

The audit experiences gained by the researchers together with the experiences of the participating companies have been used to develop the first draft of a formal audit workbook. It has been found that a software-based workbook would greatly simplify the analysis stage throughout the audit process.

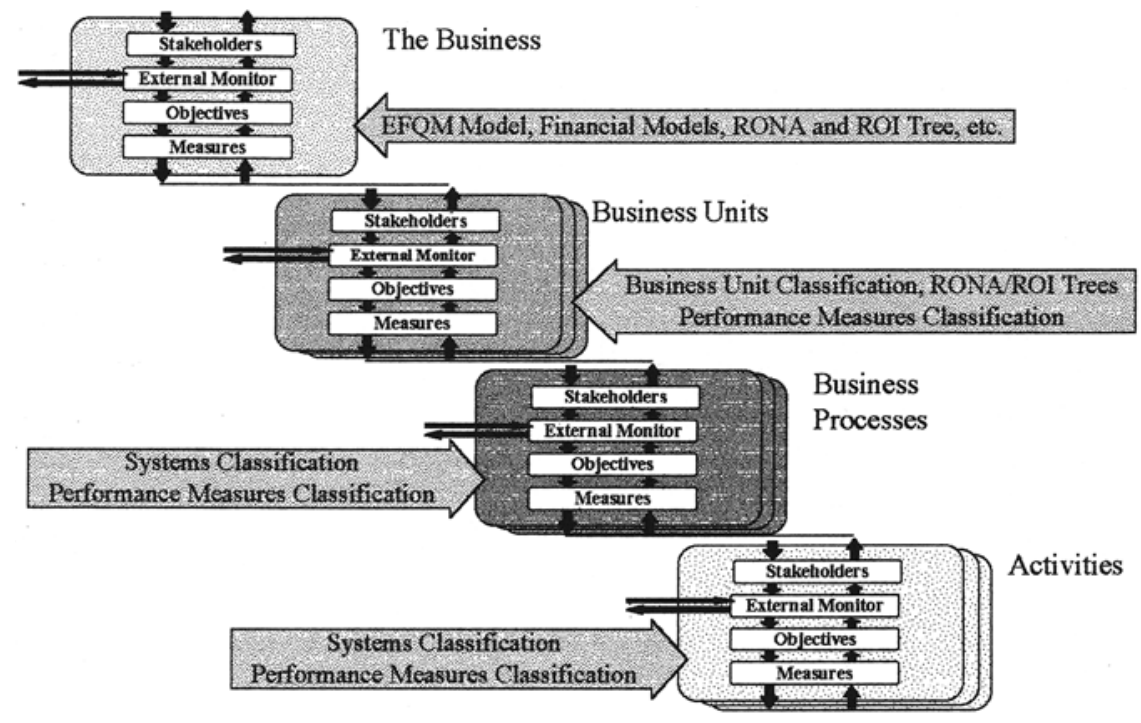

Figure 1. Reference Model for Integrated Performance Measurement Systems.

\section{CASE STUDY 1 - S. DISTRIBUTION LIMITED (SDL)}

SDL is a cost centre within the S-Corporation which specialises in the configuration of the Companies' products to customer specification before delivery. Its customers can be broadly categorised as Original Equipment Manufacturers (OEM's) - such as Sun, Compaq, Digital, Dell, Apple, etc.- and Distributors who in turn supply the high street retail outlets and specialists shops. In addition "S Distribution" has a Service and Repair Centre which offers rapid repair and replacement service to its customer and end-user base.

The researchers were invited to SDL to conduct a performance measurement system audit against the Integrated Performance Measurement System Reference Model Version 2.3. The audit results can be summarised as follows. 
- The Company's logical and physical structure is represented in Figure 2. Here it can be seen that, although logically there are three business units, the Company treats the OEM and the Retail business units as a single business.

- In general terms all stakeholders requirements are understood at all levels.

- There was a general absence of an external monitor with the exception of the areas which are monitored through the key customers Quarterly Business Revicws. This lack of visibility could compromise the Company's competitive position in the long term.

- The objectives set each level reflected most of the stakeholder's requirements, however there were some critical gaps with respect to competitive requirements of some of the business units.

- The Company did not differentiate between control and improvement measures. This lead to certain amount of confusion within the business.

- The Business Unit objectives, although clearly understood, were measured at the business level. This was because the company did not differentiate between the two logical business units (i.e. OEM and Retail). Consequently, the Company did not have a clear understanding of the level of responsiveness they were achieving at a given cost.

- The Business and Business Unit objectives were relatively well deployed to the core business processes (i.e. the Order Fulfilment Processes) with the exception of Flexibility.

- Flexibility was identified as a key order winning criteria for the OEM business unit. However, there was no evidence of a performance measure, which measured the flexibility of the OEM business unit or the OEM Order Fulfilment Process.

- The stakeholder and core business process requirements were not at all deployed to the support processes such as Engineering Support and People Capability Management. There was no evidence of a practical Resource Bargaining Process based on objective performance measures, relating to the support processes and their stakeholders' requirements.

- The performance reports did not include targets (except in some cases) and time scales which suggest that these measures are for control purposes rather than improvement.

- There was no evidence of active measures being used against each one of the performance measures relating to objectives. However, there is an improvement planning system in place in the form of action plans, which are loosely related to the business objectives.

- Although the Company had detailcd improvement plans, therc were no measures, which monitored the Company's progress and achievement of milestone targets.

- There was no evidence of an agenda to review the relevance of the performance measures. 
As a result of this IPMS audit the Company has made significant changes to its performance measurement systems to overcome the gaps identified.

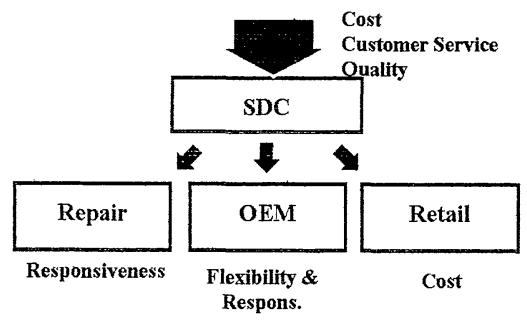

Figure 2a. Logical Structure of SDC

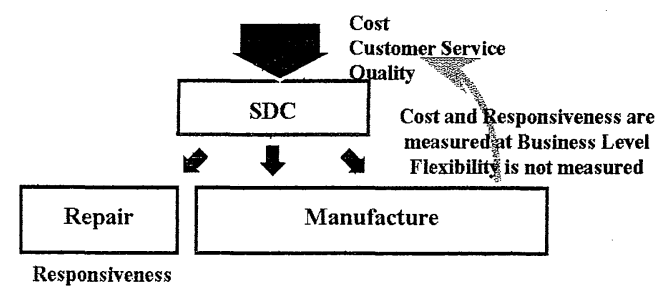

Figure 2b. Physical Structure of SDC

\section{CASE STUDY 2 - D-S LIMITED (DSL)}

DSL is a major textile manufacturer. Its main operations consist of design, manufacture, sale and distribution of gents and ladies garments such as jackets, trousers and skirts. An IPMS audit against Reference Model v.2.4 was conducted during January 1998, results of which may be summarised as follows.

- Logically DSL comprises of two business units. The Contract business unit and the Signature business unit. Physically the company recognised the two different business units and clearly differentiated between the competitive criteria associated with each business unit

- In general terms DSL was aware of its stakeholders and their requirements, but failed to recognise society as a key stakeholder.

- There was no formal External Monitor, which monitored DSL's performance with respect to its competitors. However, the senior management team demonstrated a good understanding of the Company's financial performance with respect to its key competitors.

- In most areas the objectives failed to reflect the stakeholders requirements completely and directly.

- Majority of objectives was not associated with targets and timescales.

- Critical performance measures were missing against a large number of key objectives.

- The performance of key business processes was not measured consciously, e.g. Product Development Process

- There was no differentiation between control and improvement measures.

- Majority of measures focused on cost and there was no balanced set of measures, which focused on business units or processes.

As a result of this audit, DSL included the re-design of its performance measurement system as a key objective into its BPR programme. 


\section{CASE STUDY 3 - B. MANUFACTURING LIMITED (BML)}

BML is a cost centre of a major pharmaceuticals and cosmetics manufacturer. Its main operation is the packaging of the cosmetics to the final product. In support of its packaging operations it also manufactures some of the cosmetics. An IPMS Audit, conducted during October 1997, revealed the following.

- BML comprises of three business units.

- Stakeholders requirements were fully recognised

- Although there was an awareness of competitive position it was not fully quantified

- Main objectives related to cost, quality and delivery.

- Flexibility, although and important requirement was not stated as an objective.

- The "New Product Realisation" process was considered to be the most critical process but had no measures for critical requirements of flexibility and responsiveness.

- There were a range of measures which related to business activities, but these appeared random and did not clearly relate to business process or business unit objectives.

- In general there was no differentiation between improvement and control measures.

As a result of this audit the Company made significant changes to its performance measurement systems to overcome the gaps identified.

\section{CONCLUSION}

The use of the IPMS Reference Model to audit the performance measurement system of three collaborating organisations has been demonstrated. The audit efficiently identifies deficiencies in the Company's performance measurement system.

The IPMS Reference Model has now been used in several organisations to conduct audits. In each case the audit results provided consistent and valuable feedback to the management teams. One limitation of the Audit Method is that it is still facilitator dependent. At the time of writing the research team was further developing the Audit Methodology and the associated training package to minimise its facilitator dependency. 


\section{REFERENCES}

Beer S. (1985), "Diagnosing the system for organisations", Wiley, Chichester, England.

Bititci U.S., Carrie A.S. and McDevitt L, (1996), "Performance Measurement: A Business Process View", Proceedings of the IFIP WG 5.7 Workshop on Modelling Techniques, Business Processes and Benchmarking, Bordeaux, Francc, April 1996.

Bititci, U.S., Carrie, A.S., McDevitt, L., and Turner, T, (1997), "Integrated Performance Measurement Systems: A Reference Model", Proceeding of IFIP WG 5.7 Conference on Organising The Extended Enterprise, Ascona, Switzerland.

Cross, K.F. and Lynch, R.L., (1989), "The SMART way to define and sustain success", National Productivity Review, Vol. 8 No. 1, pp. 23-33.

Dixon J.R., Nanni A.J. and Vollmann T.E, (1990), "The new performance challenge: measuring operations for world class competition", Dow JonesIrwin Homewood II, USA.

Gelders L., Mannaerts P., Maes P. (1993), "Manufacturing Strategy and Performance Indicators", Proceedings of IEPM'93, Brussels, Belgium.

Globerson, S., (1985), "Issues in developing a performance criteria system for an organisation", International Journal of Production Research, Vol. 23 No. 4, pp. 639-646.

Kaplan, R.S. and Norton, D.P., (1996), "Translating Strategy into Action -The Balanced Scorecard", Harvard Business School Press, Boston, Mass, USA.

Maskell, B.H., (1992), "Performance Measurement for World Class Manufacturing: A Model for American Companies", Productivity Press, Cambridge, MA, USA.

Neely A, Gregory M and Platts K, (1995), "Performance Measurement System Design: A Literature Review and Research Agenda", International Journal of Operations and Production Management, vol. 15 no. 4.

Russell R, (1992), "The role of Performance Measurement in Manufacturing Excellence", BPICS Conference, 1992, Birmingham, UK.

\section{BIOGRAPHIES}

Dr. Umit Bititci is the Director of the Centre for Strategic Manufacturing at the University of Strathclyde.

Professor Allan S Carrie is the Hoover Professor of Advanced Manufacturing Technology at the University of Strathclyde.

Trevor Turner is a Research Fellow at the Centre for Strategic Manufacturing.

Stefan Lutz is a Researcher at the University of Hanover in Germany. He was seconded to the IPMS project for a period of six months. 